\title{
Water saturation modeling using modified J-function constrained by rock typing method in bioclastic limestone
}

\author{
Ya Deng*, Rui Guo, Zhongyuan Tian, Limin Zhao, Dandan Hu, Hangyu Liu, and Yang Liu \\ PetroChina Research Institute of Petroleum Exploration \& Development, Beijing 100083, PR China
}

Received: 6 November 2017 / Accepted: 20 July 2020

\begin{abstract}
Combining both geological and petrophysical properties, a reliable rock typing scheme can be achieved. Two steps are included in rock typing. Step 1: rocks are classified into lithofacies based on core observations and thin sections; Step 2: lithofacies are further subdivided into rock types according to petrophysical properties such as MICP (Mercury Injection Capillary Pressure) and K-Phi relationships. By correlating rock types to electrofacies (clusters of log data), we can group the target formation into 12 rock types. Then it is possible to predict the distributions of rock types laterally and vertically using wireline logs. To avoid the defect of the classical J-function saturation model that includes permeability which is quite uncertain especially in carbonate rocks, a modified J-function was created and used in the paper. In this function, water saturation is simply expressed as a function of height above free water level for a specific rock type. Different water saturation models are established for different rock types. Finally, the water saturation model has been successfully constructed and verified to be appropriate.
\end{abstract}

\section{Introduction}

Water saturation is the key reservoir parameter in reservoir evaluation, modeling and reserve calculation. The prediction of water saturation is challenging in giant complex carbonate reservoirs for their strong heterogeneity and petrophysical complexity. The common method to calculate reservoir water saturation is the Archie formula or its extended formula, while a 3-D saturation model could be built by the constraint of water saturation calculated from well logs based on geostatistics methods [1-4]. Leverett published a paper showing how rocks with the same lithology but of different porosities and permeabilities could be described by a single function that normalizes their capillary pressure curves [5]. The J-function can then be related to water saturation of a reservoir and has been used to calculate water saturation for a long time. A defect of this classical J-function saturation model is that it includes permeability which is derived from porosity. There may be some uncertainties in the estimation of permeability, especially in carbonate rocks. We used to model saturation with the classical J-function and realized that it is not necessary to include permeability in the saturation model. Besides, lots of different equations are proposed to describe the variation of water saturation with height and reservoir

\footnotetext{
* Corresponding author: dengya@petrochina.com.cn
}

quality. And a new modified J-function was created in this study [1-12].

However, water saturation distribution calculated from the workflows above is quite far away from accuracy especially in giant carbonates characterized by complex petrophysical. That is because water saturation is not only controlled by the porosity, lithofacies, and other parameters in Archie formula, but also by pore structure, shale content and wettability that are often not consistent in carbonate reservoir $[1,2]$.

Several properties could be used to characterize carbonate reservoir; and those properties could be divided into geological and petrophysical properties. Geological properties include lithofacies, rock texture, pore types, etc., whereas petrophysical properties include porosity, permeability, wettability, capillary pressure, pore throat size distribution. To integrate the carbonate reservoir characterization and the link between geological and reservoir engineering, reservoir rock-typing methods have been developed and been used in many oil and gas fields, especially the carbonate reservoirs in Middle East [13-23]. Rock typing absorbs the geological and petrophysical connotation which is a process of classifying reservoir into distinct units and each rock type is characterized by same depositional and diagenetic processes and unique physical properties, capillary pressure curves (or J-function) and relative permeability curves [14-28]. As a result, given the rock type sets, the empirical formula for predicting reservoir parameters, such 


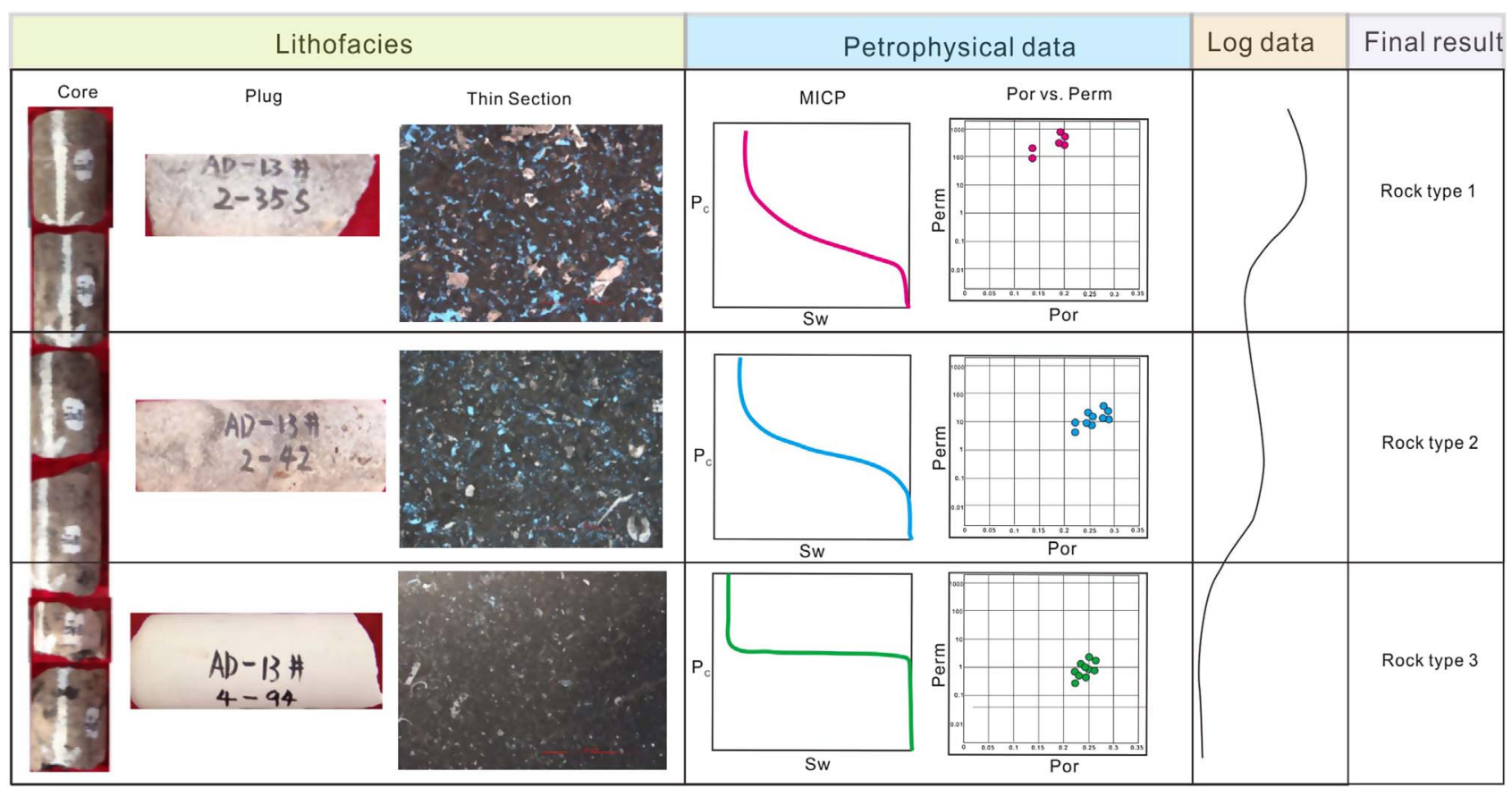

Fig. 1. Sketch of rock typing workflow.

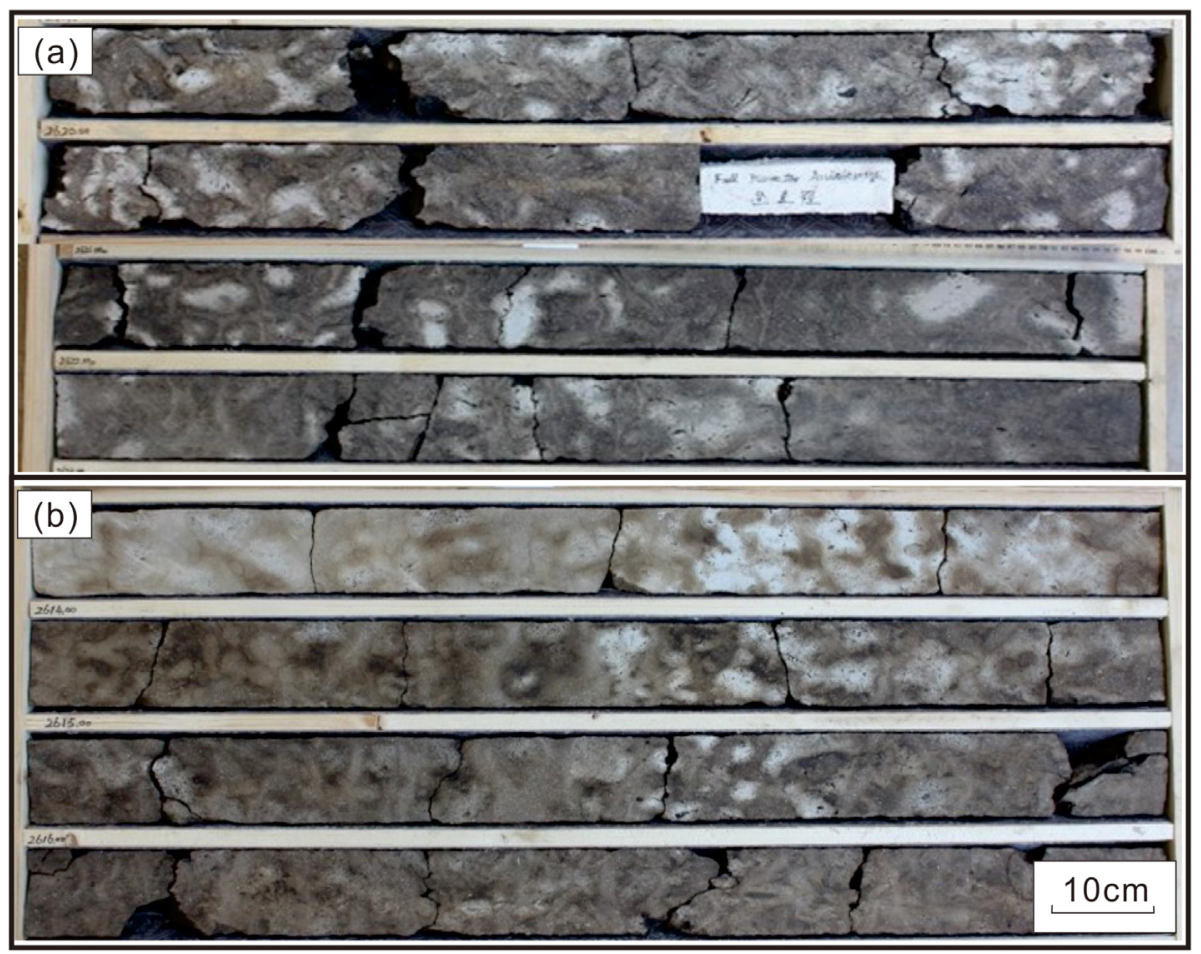

(a).KB-2,Brown limestone, granular texture, fine-medium crystalline

(b).KB-3, Dark brown breccia limestone, granular texture, fine-medium crystalline

Fig. 2. Typical core photos of KB.

as water saturation, could have been obtained from cored wells and could have been used to calculate the parameters of uncored wells and interwells to lead to an improved reservoir property model.
The studied Late Cretaceous Formation consists mainly of white, soft-hard limestone interbedded with chalky sediments. It grades upward into brown, soft-hard, porous limestone with containing fossils, calcite, and pyrite, along 

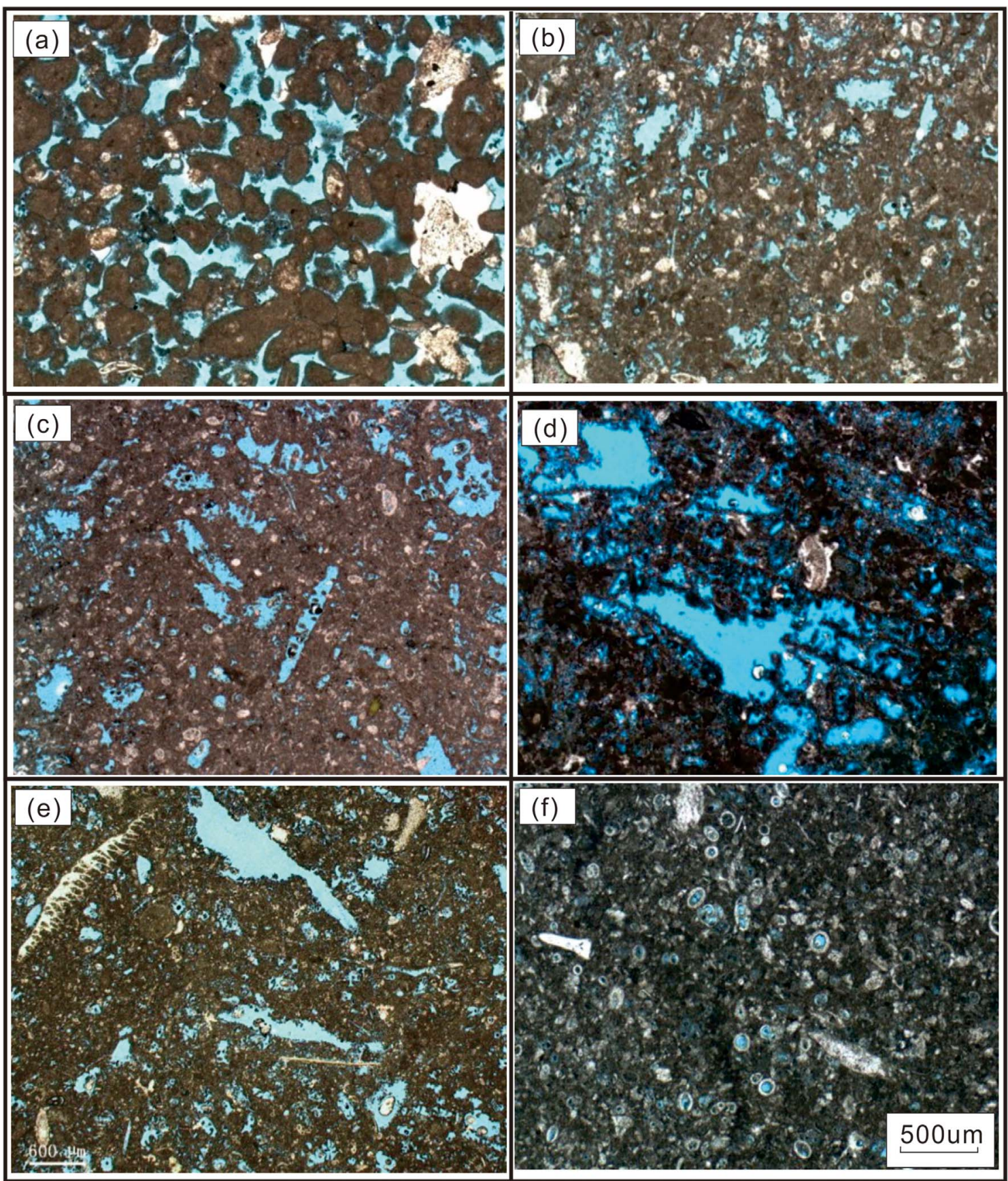

(a).KB-1, intraclastic grainstone (b).KB-2, intraclastic packstone (c).KB-2, algal wackestone

(d). KB-3 algal packstone (e).KB-3, algal wackestone (f).KB-4, globigerinida wackestone

Fig. 3. Typical thin section images of KB.

with varying degrees of oil staining. Formation thickness is $100-115 \mathrm{~m}$. Well log responses allow the formation to be divided into four major subdivisions, namely $\mathrm{KA}, \mathrm{KB}, \mathrm{KC}$ and $\mathrm{KD} . \mathrm{KB}$ is the target reservoir in this study and can be divided into 5 sublayers; they are KB-1, KB-2, KB-3, KB- 4 and KB-5. KB-1 and KB-3 can be further sub-divided into 3 sublayers and 2 sublayers, respectively. In this paper, we firstly group $\mathrm{KB}$ into different kinds of rock types and then construct different water saturation models for different rock types using the modified J-function.

\section{Rock typing process}

Classifying reservoir rocks into groups having a specific set of geological and petrophysical characteristics allows for a 


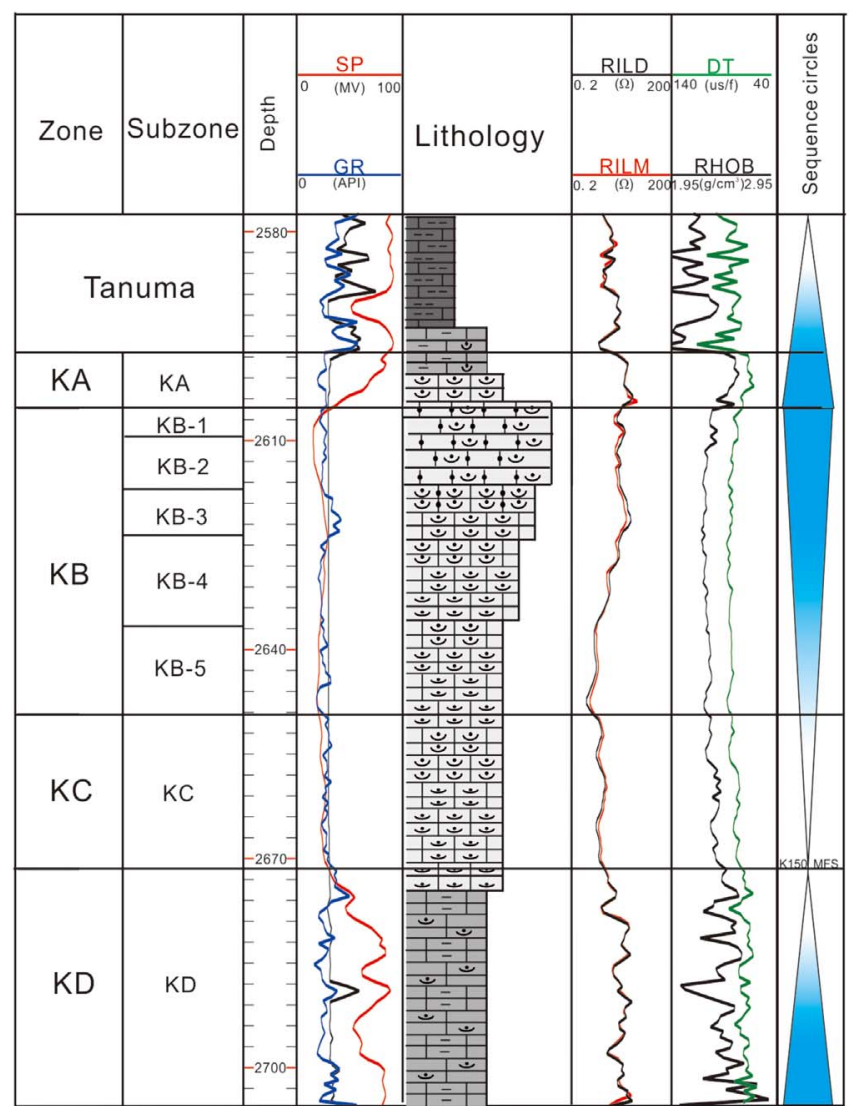

Fig. 4. Lithology of KB in a cored well.

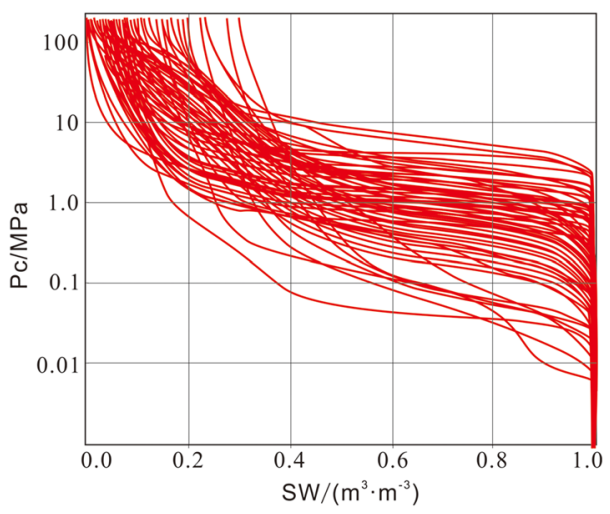

Fig. 5. MICP curves of all reservoirs.

better definition of porosity-permeability relationships, detailed reliable descriptions of the reservoir rock types, and relatively easy application of results for geomodeling purposes.

Reservoir rock typing is a fundamental building block of reservoir characterization and reservoir modeling process. There is a wide approach in defining rock types and it is highly dependent on the type of data available and the data integration [19-26]. Rock layers are generally the same "rock type". These are stratigraphic beds. Individual strata

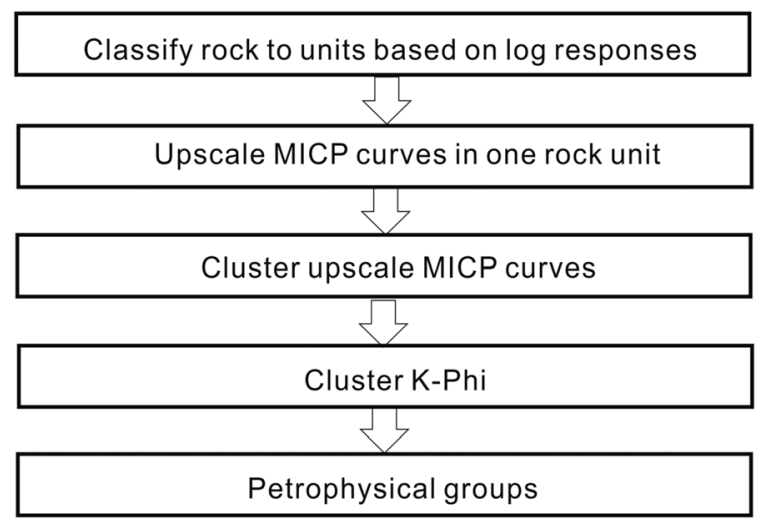

Fig. 6. Workflow for classifying petrophysical groups.

are deposited in similar depositional environments. Over time, the strata are subjected to similar burial and diagenetic processes. Individual strata often comprise a single petrophysical "rock type" which is characterized by similar fluid-flow characteristics. In carbonate strata, it is common to find more than one petrophysical "rock type" within the same stratigraphic unit.

Two domains are included in rock typing. One is the geological domain in which rocks are classified into groups according to their mineralogy, depositional textures and pore types. The second is the petrophysical domain in which petrophysical parameters, such as porosity, permeability and pore-throat size, are used to classify rocks into different groups. Conventional methods make use of data from either geological or petrophysical domain to classify rock types. However, it is believed that by combining both geological and petrophysical properties, a much more reliable rock typing scheme can be achieved. Then, by correlating rock types to electrofacies (clusters of log data), it is possible to predict the distributions of rock types laterally and vertically using wireline logs. Figure 1 shows a schematic rock typing process workflow.

Two steps are included in rock typing. Step 1: rocks are classified into lithofacies based on core observations and thin sections; Step 2: lithofacies are further subdivided into rock types according to petrophysical properties such as Mercury Injection Capillary Pressure (MICP) and K-Phi relationships.

\subsection{Classification of lithofacies groups}

In $\mathrm{KB}$, brown limestone has medium granular texture and fine to medium crystalline texture in KB-1-1 and KB-2, as shown in Figure 2. Dark brown breccia limestone has granular texture and fine to medium crystalline texture in KB-1-2 and KB-3, as shown in Figure 2. Dark brown limestone with irregularly light gray to white lamina has granular texture and medium to fine crystalline texture in KB-4. Light gray to white lime has granular texture and fine to very fine crystalline texture in KB-5.

According to the thin section identification (Fig. 3), KB-4 and KB-5 mainly consists of globigerinida wackestone, deposited in low-energy environment. Grains increase 


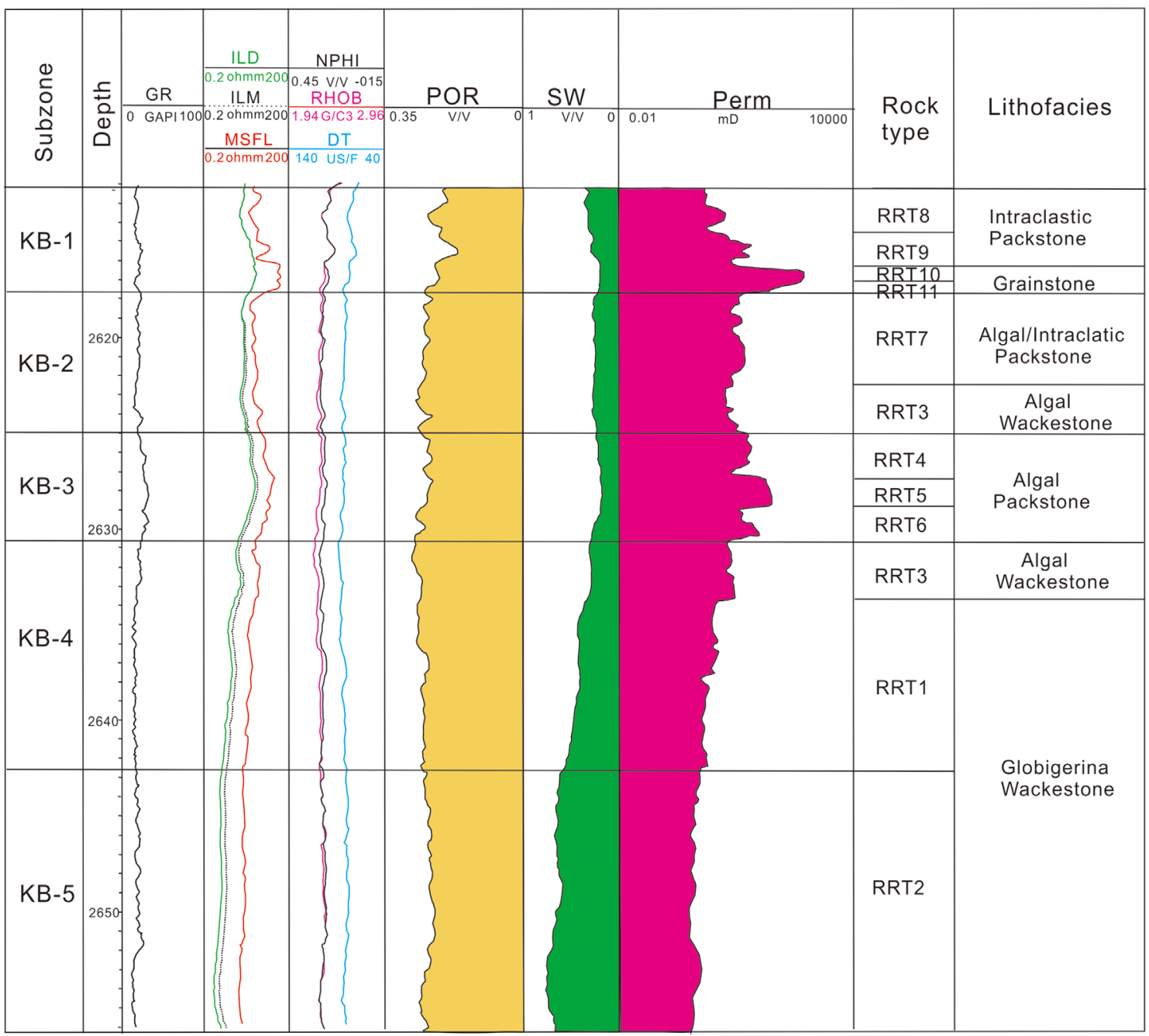

Fig. 7. Rock type classification.

in content from KB-5 to KB-4, indicating that the energy increased from KB-5 to KB-4. KB-3 mainly consists of algal packstone, deposited in shallow and quiet environments of deposition suitable for algal growth. The lower part of KB-2 consists of algal wackestone and the upper part consists of intraclastic/algal packstone. From the lower to the upper section, algal content decreases and intraclastic content increases, indicating the increased water energy not suitable for algal growth. The lower part of KB-1 consists of intraclastic grainstone and the upper part consists of intraclastic wackestone, formed in medium-high energy environments. Generally, upward-shoaling form KB-5 to KB-1, as shown in Figure 4.

\subsection{Classification of petrophysical groups}

In order to classify reservoir rocks into units with similar petrophysical properties, three input data sets are required:

(1) MICP curves, (2) core porosity measurements, and

(3) core permeability measurements. Over 210 samples have measurements of Mercury Injection Capillary Pressure (MICP) and corresponding porosity and permeability data.
The MICP curves show great variety of shapes as can be seen in Figure 5. The workflow used to classify petrophysical groups is shown in Figure 6. First, well logs such as GR, ILD and POR are used to classify reservoir rocks into units with distinguishable log responses. Due to the common significant rock property heterogeneity of carbonate rocks, within a single correlated reservoir interval, there may be several different MICP curves. Therefore, MICP curves from a single rock unit should be upscaled. The upscaled MICP curves are then clustered according to similarity of shapes. Finally, rock units with similar upscaled MICP curve shape and K-Phi relationship are classified into one rock type with a unique name. Figure 7 shows an example of rock type classification.

\section{$3 S_{w}$ modeling}

\subsection{Free Water Level estimation}

The Free Water Level (FWL) is defined as the elevation where the capillary pressure between the water phase 


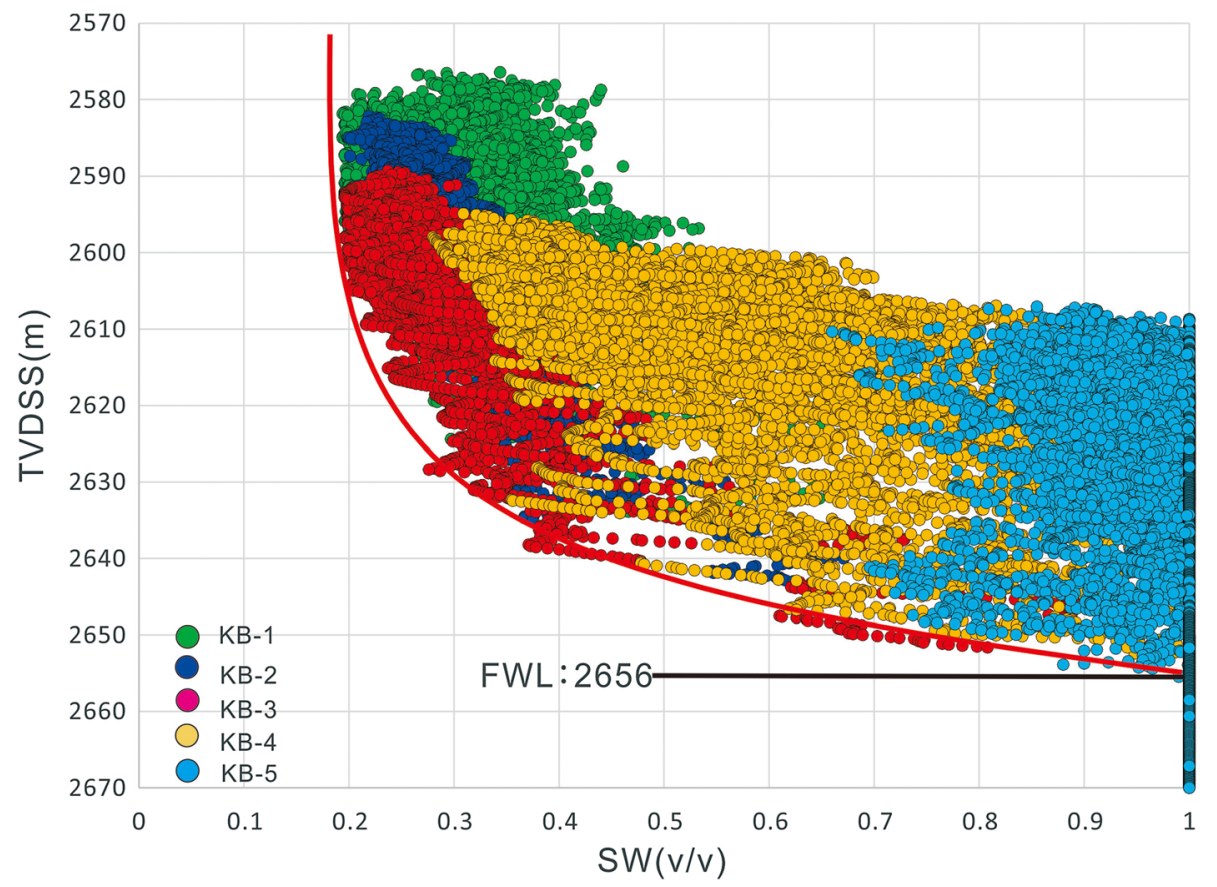

Fig. 8. Cross plots of $S_{\mathrm{w}}$ versus TVDSS to estimate FWL.

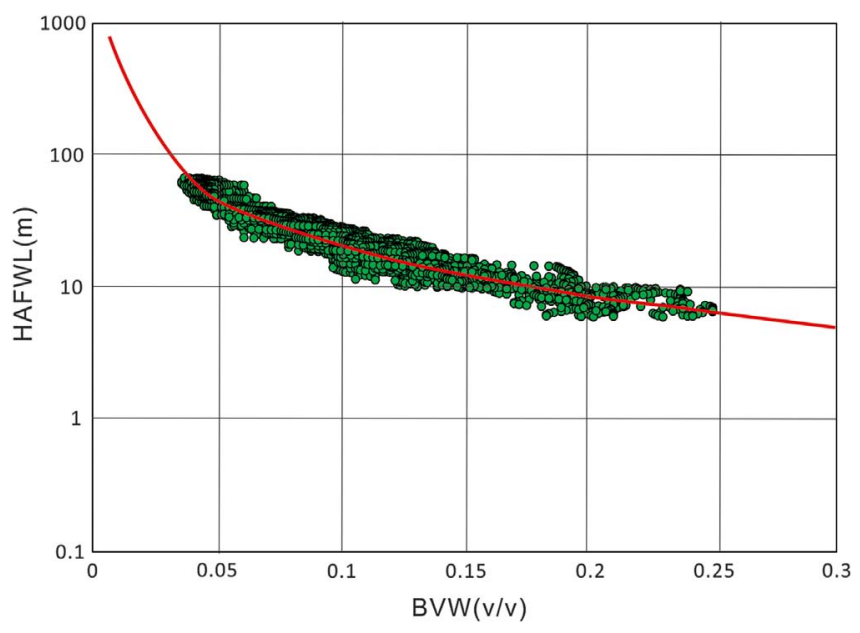

Fig. 9. Cross plot of BVW versus TVDSS.

and the less dense hydrocarbon phase is zero. For the case of a flat free water surface (no flow in the aquifer), the free water level is a single value within an equilibrium region and does not vary within the $X$ and $Y$ plane. Importantly, the free water level is not the same as the fluid contact; it occurs below the contact. The fluid contact occurs at the displacement pressure of the capillary pressure curve or, alternatively, at the J-function displacement value. The fluid contact is rock dependent; the free water level is not.

For a specific reservoir, when log-calculated water saturation is plotted versus elevation (TVDSS), the water saturation increases with depth. Since carbonate rocks are highly heterogeneous in terms of pore geometry rock types within correlated rock units based on well logs, the bestquality rock defines the lowest displacement level where $S_{\mathrm{w}}=1$. Said differently, it is also the closest level to the true FWL of that reservoir and can be considered as the apparent free water level. Therefore, on the cross plot, the lowest level where $S_{\mathrm{w}}$ approaches to 1 is taken as the free water level. It is easy to determine the FWL for KB (Fig. 8).

\subsection{Modified J-function}

Leverett published a paper showing how rocks with the same lithology but of different porosities and permeabilities could be described by a single function that normalizes their capillary pressure curves. Instead of plotting capillary pressure versus saturation, Leverett plotted the following so-called classical J-Function:

$$
J=\frac{P_{c}}{\mathrm{IFT} \times \cos (\theta)} \sqrt{\frac{k}{\phi}} .
$$

Here, $P_{\mathrm{c}}$ denotes capillary pressure, IFT is the interfacial tension, $\theta$ is the contact angle, $k$ is permeability, and $\varphi$ is porosity.

The J-function can then be related to water saturation of a reservoir and has been used to calculate water saturation for a long time. However, a defect of this classical J-function saturation model is that it includes permeability which is derived from porosity. There may be some uncertainties in the estimation of permeability, especially in carbonate rocks. We used to model saturation with the classical J-function and realized that it is not necessary to 
Table 1. Saturation models for rock types.

\begin{tabular}{lll}
\hline Rocktype & \multicolumn{1}{c}{ Lithofacies } & \multicolumn{1}{c}{ Saturation model } \\
\hline 1 & Globigerina wackestone & $S_{\mathrm{w}}=10^{(-1.914 \times \log 10(\mathrm{H})+0.962)} / \mathrm{Phi}$ \\
2 & Globigerina wackestone & $S_{\mathrm{w}}=10^{(-0.835 \times \log 10(\mathrm{H})+0.651)} / \mathrm{Phi}$ \\
3 & Algal wackestone & $S_{\mathrm{w}}=10^{(-0.557 \times \log 10(\mathrm{H})+0.144)} / \mathrm{Phi}$ \\
4 & Algal packstone & $S_{\mathrm{w}}=10^{(-0.835 \times \log 10(\mathrm{H})+0.651)} / \mathrm{Phi}$ \\
5 & Algal packstone & $S_{\mathrm{W}}=10^{(-0.564 \times \log 10(\mathrm{H})+0.177)} / \mathrm{Phi}$ \\
6 & Algal packstone & $S_{\mathrm{W}}=10^{(-0.514 \times \log 10(\mathrm{H})+0.309)} / \mathrm{Phi}$ \\
7 & Algal/intraclastic packstone & $S_{\mathrm{w}}=10^{(-0.528 \times \log 10(\mathrm{H})+0.231)} / \mathrm{Phi}$ \\
8 & Intraclastic packstone & $S_{\mathrm{w}}=10^{(-0.749 \times \log 10(\mathrm{H})+0.051)} / \mathrm{Phi}$ \\
9 & Intraclastic packstone & $S_{\mathrm{w}}=10^{(-0.749 \times \log 10(\mathrm{H})+0.051)} / \mathrm{Phi}$ \\
10 & Grainstone & $S_{\mathrm{w}}=10^{(-0.482 \times \log 10(\mathrm{H})+0.409)} / \mathrm{Phi}$ \\
11 & Grainstone & $S_{\mathrm{w}}=10^{(-0.482 \times \log 10(\mathrm{H})+0.419)} / \mathrm{Phi}$ \\
12 & Echinoderm wackestone & $S_{\mathrm{w}}=10^{(-0.581 \times \log 10(\mathrm{H})+0.137)} / \mathrm{Phi}$ \\
\hline
\end{tabular}

Here, $S_{\mathrm{w}}$ refers to water saturation, $\mathrm{H}$ refers to the height above FWL and Phi refers to porosity of the specific grid.

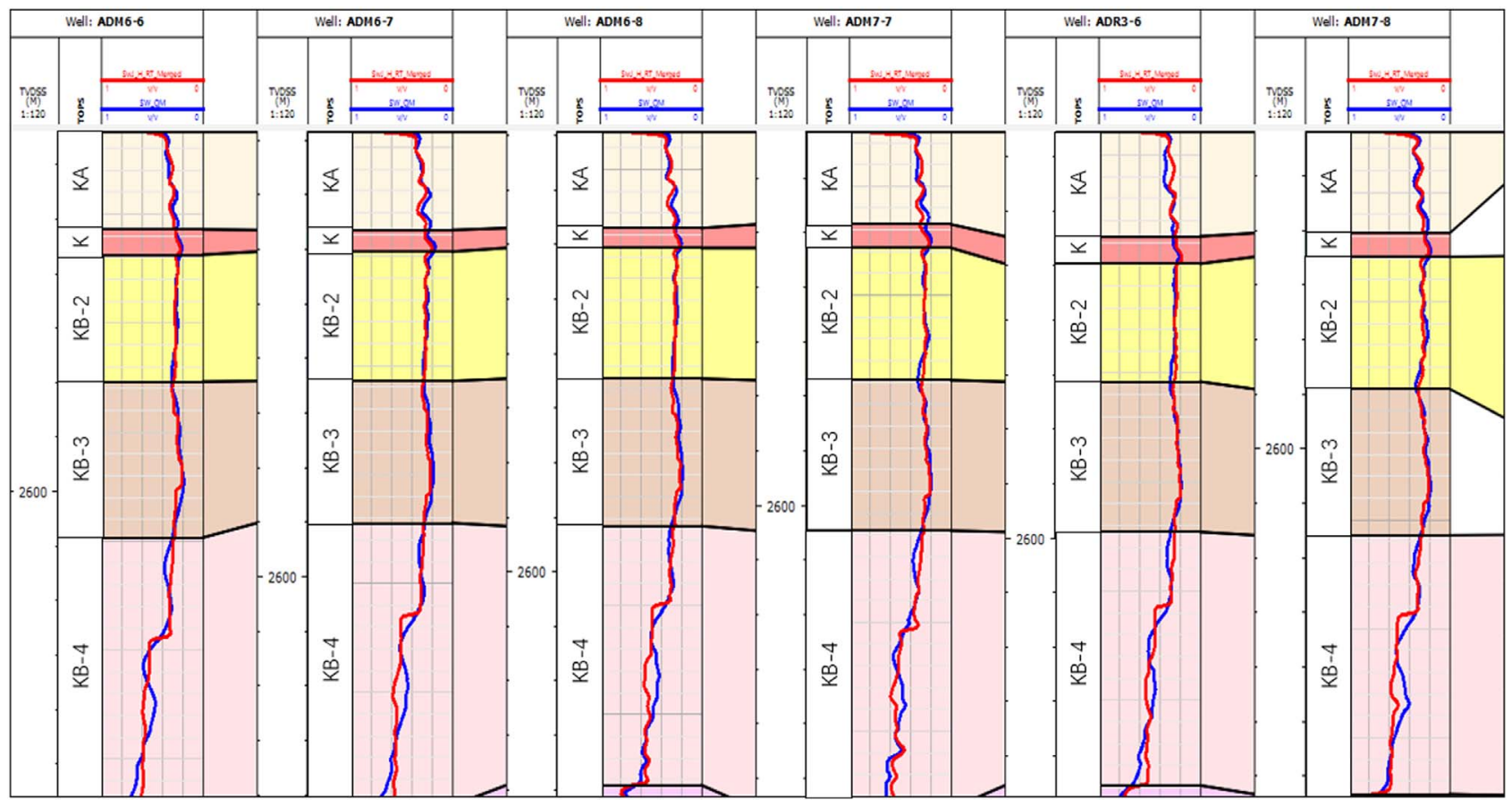

Fig. 10. Comparison between $\log S_{\mathrm{w}}$ and modeled $S_{\mathrm{w}}$ in KB.

include permeability in the saturation model. A new saturation model was created and used in the geomodels.

Since a rock type is rock unit with similar fluid flow properties, the water saturation of a specific rock type can be simply expressed as a function of height above free water level. Considering the small variation of porosity of a rock type, Bulk Volume Water (BVW) is expressed as a function of height. The following equations show how to estimate $S_{\mathrm{w}}$.

$$
H=\mathrm{FWL}-\mathrm{TVDSS},
$$

$$
\begin{gathered}
\mathrm{BVW}=S_{\mathrm{w}} \times \phi=10^{\left(a \times \log _{10}(H)+b\right)}, \\
S_{\mathrm{w}}=\frac{10^{\left(a \times \log _{10}(H)+\mathrm{b}\right)}}{\phi} .
\end{gathered}
$$

Here, " $a$ " and " $b$ " are coefficients determined by regression of BVW versus TVDSS for each rock type as shown in Figure 9. And then we can determine water saturation function for different rock types (Tab. 1). 


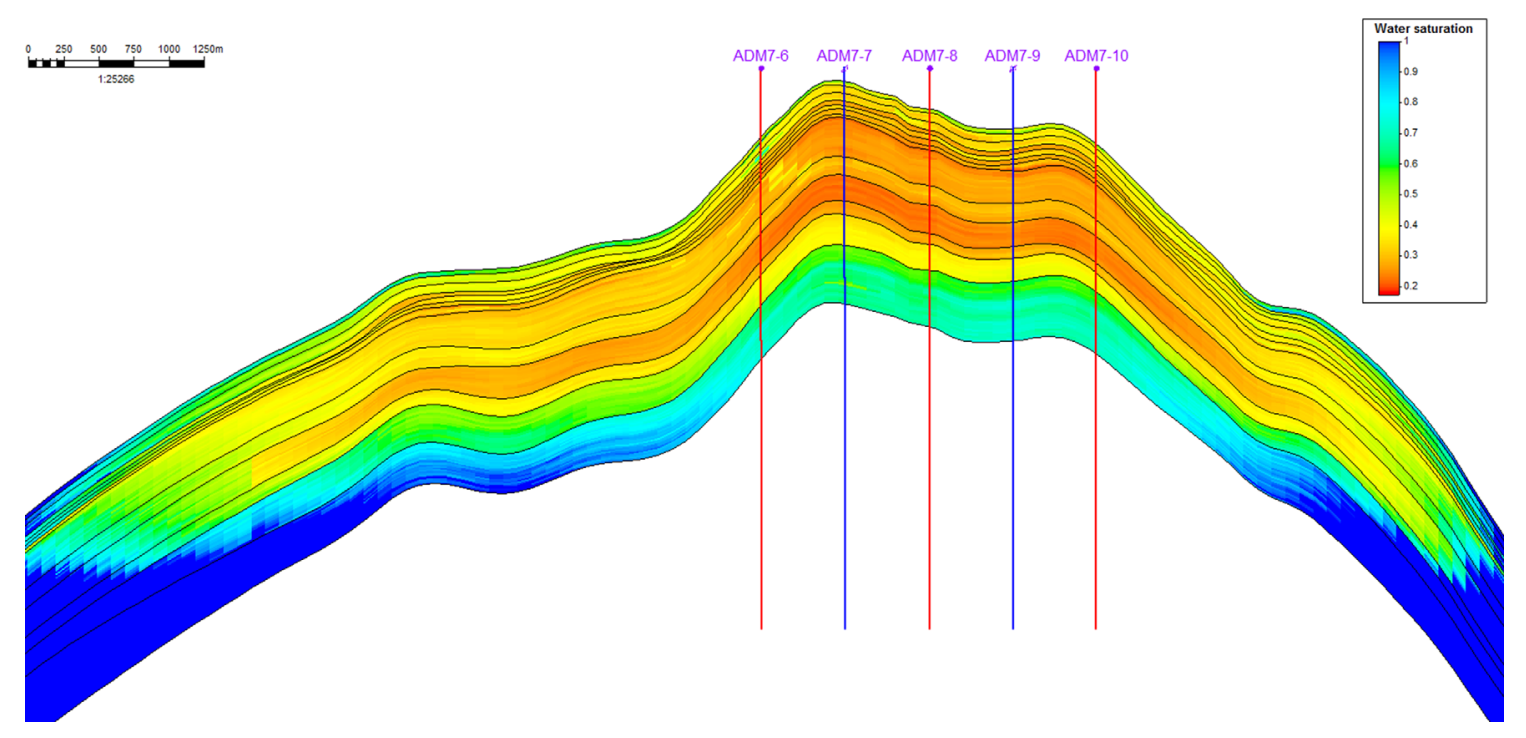

Fig. 11. Cross section of water saturation model showing the variation of $S_{\mathrm{w}}$.

\section{Results and validation}

Figure 10 shows the comparison between modeled $S_{\mathrm{w}}(\mathrm{Red})$ and $\log S_{\mathrm{w}}$ (Blue) for all layers. Overall, modeled $S_{\mathrm{w}}$ curves correlate well with well $\log S_{\mathrm{w}}$ curves except in some tight intervals. This result validates the reliability of the saturation models.

Water saturation $\left(S_{\mathrm{w}}\right)$ can then be constructed in the geomodel through the use of $S_{\mathrm{w}}$ versus height functions, one for each rock type, along with a Free Water Level (FWL). A reasonable oil-water transition zone now exists in the model. The new $S_{\mathrm{w}}$ model is more reliable (Fig. 11).

\section{Conclusion}

By combining both geological and petrophysical properties, a reliable rock typing scheme can be achieved. Two steps are included in rock typing. Step 1: rocks are classified into lithofacies based on core observations and thin sections; Step 2: lithofacies are further subdivided into rock types according to petrophysical properties such as MICP and K-Phi relationships.

To avoid the defect of the classical J-function saturation model that includes permeability which is quite uncertain especially in carbonate rocks, a modified J-function was created and used in the paper. In this function, water saturation is simply expressed as a function of height above free water level for a specific rock type. Different water saturation models are established for different rock types. Finally, the water saturation model has been successfully constructed and verified to be appropriate.

\section{References}

1 Adams S.J. (2016) Saturation-height modelling for reservoir description, The Petrophysicist Limited.
2 Harrison B., Jing X.D. (2001) Saturation-height methods and their impact on volumetric hydrocarbon in place estimates, in: SPE Annual Technical Conference and Exhibition, Society of Petroleum Engineers, New Orleans.

3 Skelt C., Harrison B. (1995) An Integrated Approach to Saturation-Height Analysis, in: 36th Annual Logging Symposium, Society of Petroleum Engineers.

4 Alger R.P., Luffel D.L., Truman R.B. (1989) New unified method of integrating core capillary pressure data with well logs, SPE Form. Eval. 4, 2, 145-152.

5 Leverett M.C. (1941) Capillary behavior in porous solids, AIME Trans. 142, 152-168.

6 Wang M. (2013) Improvement and analysis of carbonate reservoir saturation model, Journal of Southwest Petroleum University (Science \&5 Technology Edition) 35, 5, 31-40.

7 Amin A.T., Watfa M., Awad M.A. (1987) Accurate estimation of water saturations in complex carbonate reservoirs, SPE15714, Society of Petroleum Engineers.

8 Deutsch C.V. (2014) Geostatistical reservoir modeling (H), Oxford University Press, p.113.

9 Hu Y., Yu X.H., Hen G.Y. (2012) Classification of the average capillary pressure function and its application in calculating fluid saturation, Petrol. Explor. Dev. 39, 6, 733-738.

10 Elgaghah S.A., Tiab D., Osisanya S.O. (2001) A new approach for obtaining J-function in clean and shaly reservoir in situ measurements, J. Can. Petrol. Technol. 40, 7, $30-37$.

11 Obeida T.A., Al-Mehairi Y.S., Suryanarayana K. (2005) Calculation of fluid saturations from log-derived J-functions in giant complex reservoir, SPE Annual Conference and Exhibition, Dallas.

12 Basioni M., Negahban S., Dawoud A.M., Mahdi A.E., Bahamaish J.N. (2007) An empirical saturation modeling of a complex carbonate Abu Dhabi reservoir using the routine highpressure mercury and oil/water capillary pressure data, in: SPE Middle East Oil and Gas Show and Conference, 11-14 March, Manama, Bahrain.

13 Jerrylucia B. (2007) Carbonate reservoir characterization, Springer, Berlin Heidelberg. 
14 Guo G., Diaz M.A., Paz F.J., Smalley J., Waninger E.A. (2007) Rock typing as an effective tool for permeability and water-saturation modeling: A case study in a clastic reservoir in the Oriente basin, SPE Reserv. Eval. Eng. 10, 6, 730-739.

15 Amyx J.W., Bass D.M.J., Whiting R L. (1960) Petroleum reservoir engineering: physical properties, in: Petroleum Reservoir Engineering Physical Properties, McGraw-Hill, p. 610.

16 Shen P.P., Chen X.L., Qin J.S. (2010) Pressure characteristics in $\mathrm{CO}_{2}$ flooding experiments, Petrol. Explor. Dev. 37, 2, 211-215.

17 Xu C.F., Liu H.X., Qian G.B., Qin J.H. (2011) Microcosmic mechanisms of water-oil displacement in conglomerate reservoirs in Karamay Oilfield, NW China, Petrol. Explor. Dev. 38, 6, 725-732.

18 Dunham R.J. (1962) Classification of carbonates rocks according to depositional texture 1, AAPG Memoir 1, 108-121.

19 Hollis C., Vahrenkamp V., Tull S., Mookerjee A., Taberner C., Huang Y. (2010) Pore system characterization in heterogeneous carbonates: An alternative approach to widely-used rocktyping methodologies, Marine Petrol. Geol. 27, 4, 772-793.

20 Skalinski M., Gottlib-Zeh S., Moss B. (2006) Defining and predicting rock types in carbonates - preliminary results from an integrated approach using core and log data from the Tengiz field, J. Geophys. Res. Biogeosci. 47, 1, 328-340.

21 Tan X.Q., Lian P.Q., Qiu M.J., Li Y.H., Dong G.W. (2013) Rock type-constrained geological modeling of carbonate reservoirs: a case study of carbonate reservoir $\mathrm{A}$ in the Zagros Basin, Oil \& Gas Geology 34, 4, 558-564.

22 Salman S., Bellah S. (2009) Rock typing: An integrated reservoir characterization tool to construct a robust geological model in Abu Dhabi carbonate oil field, in: $S P E / E A G E$
Reservoir Characterization 8 Simulation Conference, Society of Petroleum Engineers.

23 Venkitadri V.S., Shebl H.T., Shibasaki T., Dabbouk C.A., Salman S.M. (2005) Reservoir rock type definition in a giant cretaceous carbonate, in: SPE Middle East Oil and Gas Show and Conference, Society of Petroleum Engineers.

24 Gonçalves E.C., Silva P.N.D., Silveira C.S., Carneiro G., Domingues A.B., Moss A., Pritchard T., Plastino A., de Vasconcellos Azeredo R.B. (2017) Prediction of carbonate rock type from NMR responses using data mining techniques, J. Appl. Geophys. 140, 93-101.

25 Al-Habshi A., Darwish A.R., Hamdy T., Shebl H. (2003) Application of sequence stratigraphy and petrography in preparation of reservoir rock typing scheme in one of Thamama Gas reservoirs of onshore Abu Dhabi, SPE81533, in: Middle East Oil Show, 9-12 June, Bahrain.

26 Mitra C., Riyaz K. (2009) Rock typing in a carbonate reservoir - cooperation of core and log data: case study, SPE 123703, in: SPE/EAGE Reservoir Characterization and Simulation Conference, 19-21 October, Abu Dhabi, UAE.

27 Nurul I.I., Shane L., Arns C.H. (2013) Rock-typing using the complete set of addictive morphological descriptors, SPE165989, in: SPE Reservoir Characterization and Simulation Conference and Exhibition, 16-18 September, Abu Dhabi, UAE.

28 Alhashmi N.F., Torres K., Faisal M., Segura Cornejo V., Bethapudi B.P., Mansur S., Al-Rawahi A.S. (2016) Rock typing classification and hydraulic flow units definition of one of the prolific carbonate reservoir in the onshore $\mathrm{Abu}$ Dhabi, SPE-181629-MS, in: SPE Annual Technical Conference and Exhibition, 26-28 September, Dubai, UAE. 